EVANDER CORRÊA FRAGOSO

\title{
DIREITO SUMULAR: NECESSÁRIA REVISÃO, ATUALIZAÇÃO E CONTEXTUALIZAÇÃO DOS ENUNCIADOS
}

\author{
Dissertação de Mestrado
}

Orientador: Professor Rodolfo de Camargo Mancuso

Faculdade de Direito da Universidade de São Paulo

São Paulo 
EVANDER CORRÊA FRAGOSO

\title{
DIREITO SUMULAR: NECESSÁRIA REVISÃO, ATUALIZAÇÃO E CONTEXTUALIZAÇÃO DOS ENUNCIADOS
}

\author{
Dissertação apresentada como requisito para \\ a obtenção do grau de Mestre em Direito \\ Processual Civil pelo Programa de Pós- \\ Graduação da Faculdade de Direito da \\ Universidade de São Paulo desenvolvido sob \\ a orientação do Professor Associado Rodolfo \\ de Camargo Mancuso
}

Faculdade de Direito da Universidade de São Paulo São Paulo 
Autorizo a reprodução e divulgação total ou parcial deste trabalho, por qualquer meio convencional ou eletrônico, para fins de estudo e pesquisa, desde que citada a fonte.

\title{
Serviço de Biblioteca e Documentação Faculdade de Direito da Universidade de São Paulo
}

\author{
Fragoso, Evander Corrêa
}

Direito sumular: necessária revisão, atualização e contextualização dos enunciados / Evander Corrêa Fragoso ; orientador Rodolfo Camargo Mancuso - São Paulo, 2017.

$208 \mathrm{f}$.

Dissertação (Mestrado - Programa de Pós-Graduação em Direito Processual) - Faculdade de Direito, Universidade de São Paulo, 2016.

1. Direito Sumular. 2. Processo Civil - Brasil. 3. Processo Civil Jurisprudência. I. Mancuso, Rodolfo Camargo, orient. II. Título. 
Nome: Fragoso, Evander Corrêa.

Título: Direito Sumular: Necessária Revisão, Atualização e Contextualização dos Enunciados

Dissertação apresentada como requisito para a obtenção do grau de Mestre em Direito Processual Civil pelo Programa de Pós-Graduação da Faculdade de Direito da Universidade de São Paulo desenvolvido sob a orientação do Professor Associado Rodolfo de Camargo Mancuso

Aprovada em

Banca Examinadora

Prof. Dr.: Instituição:

Julgamento: Assinatura:

Prof. Dr.: Instituição:

Julgamento: Assinatura:

Prof. Dr.: Instituição:

Julgamento: Assinatura: 


\section{AGRADECIMENTOS}

À minha família, que sempre me estimularam para o meu crescimento científico e intelectual e pela oportunidade existencial que me permitiu evoluir como ser humano.

Ao orientador Rodolfo de Camargo Mancuso, exemplo de orientação, dedicação a pesquisa e ensino, pelas lições para a vida, atenção e apoio.

Aos Professores Ricardo de Barros Leonel e Fernanda Tartuce Silva, pelas relevantes contribuições, sugestões e direcionamentos por ocasião do exame de qualificação.

Aos amigos que colaboraram para a construção desse trabalho. 
Independente dos mandamentos que são transmitidos, eles criam dificuldades para as pessoas porque, no momento em que são transmitidos, já estão desatualizados. A vida muda muito rápido, é um dinamismo, não é estática. Não é um lago de águas estagnadas, é um Ganges, flui o tempo todo. Nunca é a mesma por dois momentos consecutivos. Por isso uma coisa pode estar certa hoje e estar errada amanhã. 


\section{RESUMO}

FRAGOSO, Evander Corrêa. Direito Sumular: necessária revisão, atualização e contextualização dos enunciados. 2017. 208 f. Dissertação (Mestrado) - Faculdade de Direito, Universidade de São Paulo, São Paulo, 2017.

A presente dissertação examina o papel dos enunciados sumulares do Supremo Tribunal Federal e Superior Tribunal de Justiça no sistema processual brasileiro, à luz das reformas introduzidas na legislação e em função da serventia com que elas vêm sendo empregadas no Direito pretoriano.

Após delimitar o tema e discorrer sobre sua importância, traçamos as premissas essenciais do estudo, definindo o que seja súmula, distinguindo-a de precedente e jurisprudência.

Em seguida, fazemos uma breve abordagem do assunto do ponto de vista histórico e sob a perspectiva do Direito Estrangeiro, tendo em vista a origem na Common Law pela valorização da autoridade do precedente.

Passamos então para o capítulo central da tese. Analisamos o papel das súmulas no atual ordenamento, de acordo com o modelo de classificação visando à revisão, atualização e contextualização dos enunciados sumulares.

Finalmente, discorremos acerca de nossas conclusões, demonstrando as consequências de não haver premissas muito definidas em relação às súmulas, e ainda que um tratamento sistemático e harmônico pode ser dado ao assunto para garantir maior segurança jurídica.

Palavras-chave: revisão, atualização, contextualização, súmula, precedente judicial, jurisprudência. 


\begin{abstract}
FRAGOSO, Evander Corrêa. Required revision, updating and contextualization of sumular statements. 2017. $208 \mathrm{f}$. Master's dissertation - Faculty of Law, University of São Paulo, São Paulo, 2017.

The present thesis analyzes the sumular statement role of Brazil's Supremo Tribunal Federal and Superior Tribunal de Justiça within the brazilian procedural system, in light of the recent reforms introduced in the legislation and due to the usefulness with which they are being used in praetorian law.

After delimitating the matter and discussing its importance, we have outlined the assumptions which are essential for the study, defining what sumular statement is, distinguishing it from judicial precedent and Jurisprudence.

Following, we have briefly aproached the matter under a historical point of view and under the perspective of the common law.

And then we went to the core chapter of the thesis. We have analyzed the role that the summular statement plays in the existing legal system, in accordance wih its classification standard to revision, updating and contextualization of summular statements.

Finally, we have explained our conclusions, showing the consequences of no welldefined assumptions relates to the statements, yet, a systematic and harmonic treatment that can be given to the matter in order to ensure greater legal certainty.
\end{abstract}

Keywords: revision, updating, contextualization, sumular statement, judicial precedent, Jurisprudence. 


\section{SUMÁRIO}

1 - INTRODUÇÃ O..............................................................................................................8

2 - CONSIDERAÇÕES GERAIS DE DIREITO SUMULAR..........................10

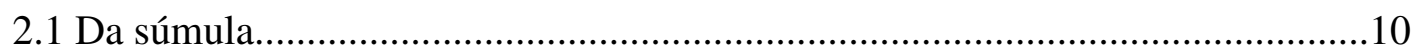

2.2 Precedente, jurisprudência e súmula: aclaramentos conceituais........................10

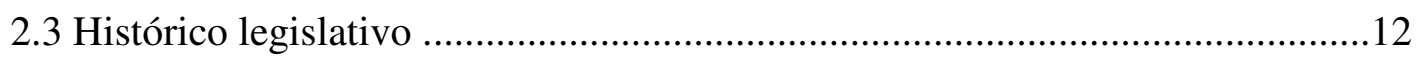

2.4 Origem histórica das súmulas: os assentos em Portugal...................................14

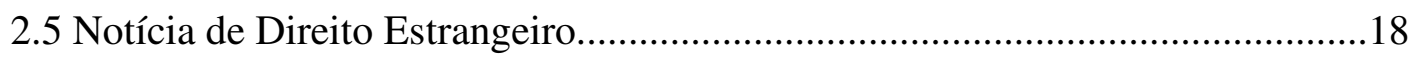

\section{3 - EDIÇÃO, NATUREZA E CRITÉRIOS DISTINTIVOS DOS}

ENUNCIADOS SUMULARES ....................................................................................22

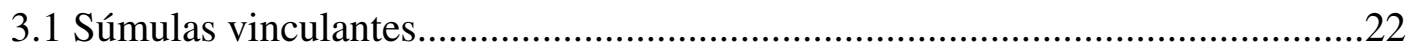

3.2 Súmulas do Supremo Tribunal Federal e do Superior Tribunal de Justiça .......24

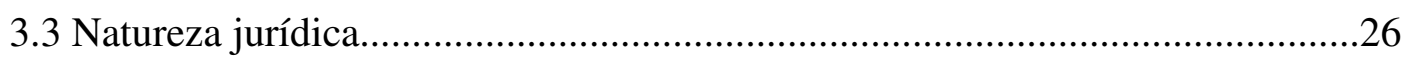

3.4 Critérios de classificação em conformidade com a ordem normativa.................30

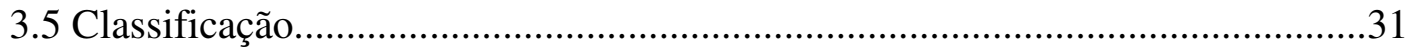

4 - SÚMULAS VINCULANTES E SÚMULAS DO STF E DO STJ..................34

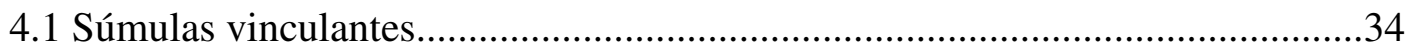

4.2 Súmulas do Supremo Tribunal Federal.........................................................54

4.3 Súmulas do Superior Tribunal de Justiça.....................................................138

5 - CONSIDERAÇÕES CONCLUSIVAS.................................................199

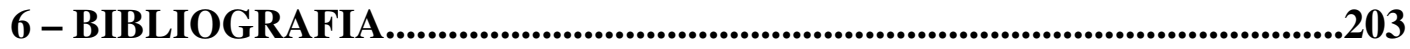




\section{INTRODUÇÃO}

O renovado panorama do ordenamento jurídico brasileiro, em especial a partir das modificações havidas com o Código de Processo Civil vigente, trouxe à tona um novo ambiente pretoriano, com marcantes alterações no que tange à disciplina legal da jurisprudência e dos precedentes. Sob esse aspecto, a utilização da súmula como um extrato de julgamento para formação do precedente judicial tende a ser exacerbado.

Em verdade, as súmulas no Direito Brasileiro, tal como surgidas na primeira metade da década de 60 do século XX, têm por papel primordial exatamente este: o de limitar as mais diversas teses jurídicas que soem ocorrer nos mais diversos diplomas legais, fixando-as. Trata-se, pois, de uma metodologia que se labora a partir da interpretação legal decorrente de reiteradas decisões das cortes superiores ${ }^{1}$.

Sem embargo da inegável influência ou até mesmo pressão que a existência de determinada súmula imprime sobre o processo decisório nos pronunciamentos judiciais, não há negar que, de ordinário, a força persuasiva das súmulas é posta em dúvida, em função das diversas interpretações operativas e doutrinais, da coerência sistêmica em relação ao ordenamento jurídico, bem como dos vícios no conteúdo do enunciado sumular.

Malgrado a possibilidade de revisão e cancelamento de enunciados sumulares, acaba acontecendo que, em função dessas possibilidades retro mencionadas, o direito pretoriano se enlaceia a uma série de enunciados sumulares, que não possuem, no mais das vezes, limitação e clareza no que tange à aplicação das súmulas.

Dada a aptidão dos enunciados sumulares para a uniformidade de tratamento de casos idênticos, com vistas à agilidade aos andamentos processuais e à segurança das decisões judiciais, não é possível ao aplicador do direito, de forma prática e coerente, captar o grau de vinculatividade dos enunciados sem um percuciente exame. Em função desse contratempo corriqueiro da práxis judiciária, surgiu a proposta deste trabalho de revisar, retificar e corrigir os extratos sumulares do STF e do STJ de acordo com as

\footnotetext{
${ }^{1}$ No ponto, afirma ELIAS, Gustavo Terra: “A súmula não escapa da sombra da interpretação. A interpretação da lei, que o Judiciário, em virtude das súmulas, supostamente, uniformizou, muitas das vezes não se esgota, e, paradoxalmente, corre o risco de renovar-se com os verbetes sumulares" (Súmula vinculante n. 3 do STF: um estudo do conflito entre as mutações do direito e a busca de segurança jurídica no controle dos atos de aposentadoria pelos Tribunais de Contas. Interesse Público, ${ }^{\circ} 73$, maio/jun. 2012, p. 198).
} 
mudanças de entendimento desses tribunais superiores, a par de atualizar, trazendo à lume as inovações no direito pretoriano que afetaram a interpretação originária dos enunciados, e contextualizar, trazendo os extratos sumulares sob a nova perspectiva processual encampada com o Código de Processo Civil.

A importância do tema pode ser posta em evidência pela redação o artigo 927, inciso IV, do Código de Processo Civil, que prevê: "Art. 927. Os juízes e tribunais observarão: IV - os enunciados das súmulas do Supremo Tribunal Federal em matéria constitucional e do Superior Tribunal de Justiça em matéria infraconstitucional". O novo papel a ser desempenhado pelas súmulas sob o amparo do novo diploma processual, em relação à sua integração e complementaridade, exsurge daí, com força impositiva ressonante.

Servindo a tal intento, o presente estudo trata no primeiro plano de direito sumular, resvalando no instituto da súmula, origem, breve análise histórica que originou as súmulas no Direito Brasileiro, além de notícias de direito estrangeiro.

Em segundo plano, sem qualquer pretensão de limitar o tema, adotar, a partir de um modelo classificatório elaborado em co-participação com o Prof. Mancuso, que facilite a operacionalização dos enunciados sumulares ora delimitados, considerando os critérios de formalidade mandamental, constitutivo e sistêmico exigidos para as súmulas, de modo a compreender melhor a operacionalidade desses enunciados.

A limitação de exame aos enunciados sumulares do E. Supremo Tribunal Federal e do C. Superior Tribunal de Justiça para os propósitos desse estudo deve-se à maior representatividade da matéria examinada pelas cortes superiores quando da edição e aprovação das súmulas, além da relevância da jurisprudência dessas cortes de sobreposição a ser observada pelos tribunais e juízos hierarquicamente inferiores. 


\section{CONSIDERAÇÕES CONCLUSIVAS}

1) Com o escopo de traduzir a interpretação predominante e reiterada dos tribunais, as súmulas distanciam-se dos demais pronunciamentos judiciais exatamente por essa origem na uniformização dos julgados de reiterados precedentes.

Além desse papel de mecanismo de facilitação de casos repetitivos, as súmulas exercem a função de indicar a compreensão dos tribunais sobre a aplicação do Direito. Assim, ao mesmo tempo em que uniformizam as situações pretéritas, devem ter uma visão prospectiva, capaz de acompanhar a evolução do Direito pátrio.

Nesse processo, ainda que sirvam para garantir segurança jurídica, as súmulas, que tem por base as circunstâncias fáticas dos casos que lhes deram origem, não escapam às alterações da vida contemporânea.

O que se pretendeu indicar por meio desta Dissertação é que, não bastasse a mudança dos contextos fáticos, as deficiências ao longo processo de edição das súmulas influencia decisivamente a aplicabilidade desses enunciados, permitindo que pairem no sistema súmulas defasadas, contrárias à lei, substituídas ou mesmo que necessitem de confirmação. E o Direito Sumular, que deveria auxiliar no desenvolvimento do Direito, acaba por produzir o efeito inverso de segurança jurídica.

2) A partir da perspectiva histórica, entendemos a origem do instituto no Direito Pátrio com a criação dos enunciados de súmula da jurisprudência predominante do Supremo Tribunal Federal, que foram paulatinamente adquirindo posição de proeminência do ordenamento, como instrumento de valorização dos precedentes, através da edição das Leis 9.139/95, 9.756/98, 10.352/2001, culminando com a Emenda Constitucional 45/2004, $11.276 / 2006,11.418 / 2006$ e 13.105/2015.

Observamos que, malgrado a sua inequívoca origem no assento português, o instituto, tal como lançado no direito brasileiro, não encontra equivalente estrangeiro hodiernamente, apesar de ser possível vislumbrar, na adoção das súmulas vinculantes, 
criadas a partir da EC 45/2004, essa referência no modelo anglo-saxão de valorização da autoridade do precedente.

Quanto ao procedimento previsto na Lei 11.417/2006 específico às súmulas vinculantes, observamos que elas foram regulamentadas, abrangendo a legitimação e intervenção de terceiros, objeto e requisitos, procedimento de elaboração, revisão e cancelamento, mecanismo de impugnação, entre outros.

Enfim, somente após uma visão geral de enquadramento do instituto no ordenamento brasileiro, nos foi possível examinar a natureza do enunciado sumular, considerando o disposto no artigo 927 do Código de Processo Civil.

Evidenciado o caráter propositivos-descritivos dos enunciados sumulares, decorrentes de atividade administrativa, ganhou importância o enquadramento das súmulas do Supremo Tribunal Federal e do Superior Tribunal de Justiça, inseridas no contexto dos critérios mandamental, constitutivo e sistêmico.

Finalmente, após a revisão, atualização e contextualização dos enunciados, identificamos dados quantitativos indicativos para especificação desses enunciados no Direito Pátrio.

3) Em relação às súmulas vinculantes, foi possível perceber várias nuances características do processo de edição das súmulas. Em primeiro lugar, a natureza eminentemente política de edição dos referidos dispositivos. Alguns ministros até comentaram, em seus votos, o receio que tinham em razão do modo como "chegavam" à súmula vinculante. Conquanto o Supremo Tribunal Federal adote critérios variados, como a repercussão geral ou jurisprudência dominante sobre este ou aquele tema, o fato é que a edição das súmulas de efeito vinculante resvala no mais das vezes na conveniência dos Ministros e/ou pressão de agentes políticos. É o caso, por exemplo, da Súmula $n^{\circ} 11$, que disciplina o uso das algemas.

Por outro lado, ficou evidente que o procedimento a ser adotado também não é dos mais claros. O Min. Marco Aurélio, por repetidas vezes, quando da votação para aprovação de súmulas, levantava a necessidade de a proposta de súmula passar pela Comissão de Jurisprudência. Apesar de aberta a possibilidade de auxílio pelo "amicus curiae" e da necessidade de vista do Procurador-Geral da República, na edição de todas as súmulas, a 
atuação deles teve papel secundário, na grande parte das vezes apenas ratificando a proposta apresentada. Quando em sessão, no geral, a discussão derivava para questões vernáculas.

No que tange à matéria, não necessariamente proposta de súmula passa antes por "reiteradas decisões sobre matéria constitucional" (v. art. 103-A da Constituição Federal), como expôs o Min. Joaquim Barbosa em relação à Súmula no 24. Por outro lado, tampouco tem necessidade, na prática, a controvérsia atual (cf. art. 103-A). É o caso, por exemplo, das súmulas que foram confirmadas como vinculantes.

Podemos inferir, portanto, que o procedimento detalhado na Lei 11. 417/2006 é adotado de forma limitada na prática.

4) Após exame quantitativo das súmulas, vinculantes ou não, chegamos às seguintes ponderações:

Em relação às súmulas vinculantes, considerando a elaboração de 56 (cinquenta e seis) enunciados desde a sua previsão, nos dez anos de aprovação da primeira súmula, há uma média razoável de edição de aproximadamente uma súmula a cada dois (2) meses. O que não parece razoável, contudo, é a excessiva edição de súmulas confirmadas como vinculantes (dezoito), o que evidencia que as súmulas em geral não são de conhecimento dos operadores de Direito em geral, a ponto de serem necessárias sua confirmação como vinculantes.

Em relação às sumulas persuasivas, no âmbito do Supremo Tribunal Federal, das 736 (setecentas e trinta e seis) súmulas, de acordo com os critérios estabelecidos no estudo, observamos 373 (trezentas e setenta e três) que foram mantidas integralmente, 34 (trinta e quatro) praeter legem, 18 (dezoito) confirmadas como vinculantes, 9 (nove) redundantes, 5 (cinco) canceladas, 4 (quatro) revogadas e 1 (uma) substituída. Em relação a essas súmulas, ainda que se vislumbre certa falta de zelo quanto à superveniência de súmulas redundantes ou que sejam posteriormente confirmadas, não há propriamente um equívoco no Direito Pretoriano no que tange à correta aplicação desses enunciados. Contudo, observamos 261 (duzentas e sessenta e uma) defasadas, 14 (catorze) derrogadas, 10 (dez) inconstitucionais, 6 (seis) contra legem e 1 (uma) súmula conflitante. 
No âmbito do Superior Tribunal de Justiça, das 582 (quinhentas e oitenta e duas) súmulas, de acordo com os critérios estabelecidos no estudo, observamos 460 (quatrocentas e sessenta) que foram mantidas integralmente, 37 (trinta e sete) praeter legem, 18 (dezoito) canceladas, 18 (dezoito) remissivas, 5 (cinco) substituídas e (1) uma redundante, além de trinta e cinco (35) defasadas, três (3) derrogadas, três (3) inconstitucionais, uma (1) contra legem e uma (1) conflitante.

Portanto, considerando as súmulas inconsistentes com a legislação vigente, canceladas, ratificadas ou revogadas, limitadas em seu âmbito de aplicação ou ainda redundantes, apurou-se o percentual de 43\% (320 de 736) em relação ao Supremo Tribunal Federal e de 14\% (85 de 582) em relação ao Superior Tribunal de Justiça.

Dessas, o alto número de súmulas defasadas é o que causa mais assombro. Ainda que boa parte delas não causem maiores dúvidas, o fato é que outras tantas são rotineiramente empregadas no Direito Pretoriano. Com a legislação superveniente, muitas tiveram suprimida a base jurídica que as sustentavam. Por mais que a "solução" seja relativamente simples, apenas deixar de aplicar as súmulas desatualizadas ${ }^{479}$, uma edição periódica pelos Tribunais, com a supressão das súmulas já “extirpadas” do ordenamento, traria maior segurança para os aplicadores do Direito.

\footnotetext{
${ }^{479}$ Como bem ressaltado pelo Ministro do Superior Tribunal de Justiça, Mauro Campbell Marques, por mais que os textos estejam ultrapassados, a revogação dessas súmulas não seria possível, "sob pena de afetar as ações que já estão em tramitação" (Disponível em [http://jota.info/justica/com-novo-cpc-stj-deve-flexibilizarefeitos-de-cinco-sumulas-14062016]. Acesso em 12-09-2016).
} 


\section{BIBLIOGRAFIA}

ABBOUD, Georges. Súmula vinculante versus precedentes: notas para evitar alguns enganos. Revista de Processo, São Paulo, v.33, n.165, pp. 218-30, nov. 2008.

Precedente Judicial versus Jurisprudência dotada de efeito vinculante. In: WAMBIER, Teresa (coord.). Direito Jurisprudencial. São Paulo: RT, 2012. pp. 491-552.

ALMEIDA, Fernando Dias Menezes de. Súmula do Supremo Tribunal Federal: natureza e interpretação. Revista de Direito Constitucional e Internacional, São Paulo, v.14, n.57, p.223-34, out./dez. 2006.

AZEVEDO, Álvaro Villaça. Enciclopedia Saraiva 8. São Paulo: Saraiva, 1978.

AZEVEDO, Luiz Carlos de. O Direito Visigótico. Revista da Fadusp, São Paulo, v. 96, 2001.

AZEVEDO, Luiz Carlos de. O reinado de D. Manuel e as Ordenações Manuelinas. Revista da Fadusp, São Paulo, v. 95, 2000.

BARROS, Marco Antonio de. Anotações sobre o efeito vinculante. Revista dos Tribunais. Sao Paulo, v.86, n.735, pp.100-6, jan. 1997.

BENJÓ, Bela. Considerações sobre a súmula da jurisprudência predominante. Revista de Direito do Tribunal de Justiça do Estado do Rio de Janeiro. Rio de Janeiro, n.53, pp.386-8. out./dez. 2002.

BLACK, Henry Campbell. Black's law dictionary. 6 ed. St. Paul: West Publishing, 1991.

BUSTAMANTE, Thomas; TEIXEIRA, Alice; MACIEL, Gláucio [et al.]. A força normativa do direito judicial: uma análise da aplicação prática do precedente no direito brasileiro e dos seus desafios para a legitimação da autoridade do poder judiciário. Brasília: Conselho Nacional de Justiça, 2015.

CANOTILHO, Direito Constitucional e Teoria da Constituição. 7 ed. Coimbra: Almedina, 2003. 
COLE, Charles D. Stare decisis na cultura jurídica dos Estados Unidos. O sistema de precedente vinculante do common law. Revista dos Tribunais vol. 752. São Paulo: RT, ano 87, jun. 1998.

CUNHA, Sérgio Sérvulo da. Aplicação da Súmula Vinculante. Revista Trimestral de Direito Público, Madrid, n.46, pp. 94-102, 2004.

CURY, Marcelo. Virou súmula. Revista do Instituto de Pesquisas e Estudos. Bauru. n.39. pp. 303-6. jan./abr. 2004.

DAVID, Rene. Os grandes sistemas do direito contemporâneo. São Paulo: Martins Fontes, 2002 .

DAVID, Tiago Bittencourt. Novo CPC não obriga juízes a se vincularem a entendimentos de STF e STJ. Disponível em: [http://www.conjur.com.br/2015-abr-11/tiago-david-cpcnao-vincula-juizes-sumulas-stf-stj]. Acesso em 20 de outubro de 2016.

DEBATES E PROPOSTAS DAS SÚMULAS VINCULANTES nº 1 a 3, 4 a 6, 7 a 10, 11 a $13,14,15,16,17,18,19,20,21,22,23,24,25,26,27,28,29,30,31,32,33,34,35,36$, 37, 38, 39, 40, 41, 42, 43, 44, 45, 46, 47, 48, 49, 50, 51, 52, 53, 54, 55 e 56. Disponível em [http://www.stf.jus.br/ portal/cms/verTexto.asp?servico=jurisprudenciaSumulaVinculante]

DIDIER JR., Fredie. Curso de Direito Processual Civil. 2 ed. Salvador: Podivm, 2008.

DOBBINS, Jeffrey C. Structure and Precedent. Michigan Law Review, Ann Arbor, v.108, n.8, pp.1453-96, Jun. 2010.

ELIAS, Gustavo Terra. Súmula vinculante n. 3 do STF: um estudo do conflito entre as mutações do direito e a busca de segurança jurídica no controle dos atos de aposentadoria pelos Tribunais de Contas. Revista Interesse Público. n. 73. Porto Alegre, maio/jun. 2012.

FALCÃO, M.; HAUBERT, M. Procuradoria pede demissão de parentes de três senadores, O Estado de São Paulo, São Paulo, p. A9, 21 jan. 2016.

FREUND, Paul. Aspectos do Direito Americano. Rio: Forense, 1963. 
GAIO JUNIOR, Antonio Pereira. Predicados da súmula vinculante: objeto, eficácia e outros desdobramentos. Revista de Processo. São Paulo. v.37. n.207. p.25-42. maio. 2012.

HARADA, Kiyoshi. Desigualdade na partilha. Portal Jurídico investidura. Abr. 2010. Disponível em: [http://investidura.com.br/biblioteca-juridica/artigos/direito-civil/157091]. Acesso em: 12 dez. 2015.

HESPANHA, Manuel Antonio. Historia das Instituições: época medieval e moderna. Coimbra: Almedina, 1982.

HIGASHIYAMA, Eduardo. Teoria do direito sumular. Revista de Processo. São Paulo. v.36, n.200, pp.71-124, out. 2011.

KELSEN, Hans. Teoria pura do direito. Coimbra: Armenio Amado, 1984, 6 ed..

LAZZARINI, Alexandre Alves. A indução generalizadora na elaboração da jurisprudência. Revista de Processo. São Paulo, v.21, n.83, pp.246-54, jul./set. 1996.

LEAL, Victor Nunes. Atualidade do ST. Revista Forense, Rio, v. 208, 1964.

LEITE, Rosimeire Ventura, Organização Judiciária nas Ordenações Manuelinas. Revista da Fadusp, São Paulo, v. 101, jan/dez 2006.

LINS NETO, Edmundo. Sumula. Revista de Processo. Sao Paulo, v.14, n.53, pp. 222-224, jan./mar. 1989.

LOPES FILHO, Juraci Mourão. Os Precedentes Judiciais no Constitucionalismo Contemporâneo. Salvador: Juspodium, 2014.

LUCON, Paulo. Honorários Advocatícios no CPC de 2015. In: Novo Código de Processo Civil: principais alterações, 2 ed. São Paulo: Rideel, 2016.

MACHADO, Agapito. As sumulas do TFR face a Nova Constituição Federal. Revista Ajufe. Sao Paulo. v.8, n.24, pp.21, mar./abr. 1989.

MACIEL JUNIOR, Vicente de Paula. O efeito vinculativo das sumulas e enunciados. Revista da Faculdade de Direito da Universidade Federal de Minas Gerais. Belo Horizonte. v.34, n.34, pp. 159-70, 1994. 
MANCUSO, Rodolfo de Camargo. -- A Jurisprudência, dominante ou sumulada, e sua eficacia contemporânea. Revista do Tribunal de Contas do Município de São Paulo. São Paulo, v.1, n.3, p. 40-47, ago. 1999.

. Divergência Jurisprudencial e Súmula Vinculante. 5 ed. São Paulo: RT, 2013.

Sistema Brasileiro de Precedentes: natureza, eficácia, operacionalidade. São Paulo: RT, 2015.

MARINONI, Luiz Guilherme. Eficácia vinculante: à ênfase à ratio decidendi e à força obrigatória dos precedentes. Revista de Processo. São Paulo, v.35, n.184, pp. 9-41, jun. 2010.

O STJ enquanto Corte de Precedentes: recompreensão do sistema processual da corte suprema. 2 ed. São Paulo: RT, 2014.

. Precedentes Obrigatórios. São Paulo: RT, 2010.

MEDINA, José Miguel Garcia; WAMBIER, Luiz Rodrigues; WAMBIER, Teresa Arruda Alvim. A súmula vinculante, vista como meio legítimo para diminuir a sobrecarga de trabalho dos tribunais brasileiros. Revista do Advogado. São Paulo, v.27, n.92,. jul. 2007.

MEDINA, José Miguel Garcia; GUIMARÃES, Rafael de Oliveira. Breves Considerações sobre os Embargos de Declaração no novo CPC. In: Novo Código de Processo Civil: principais alterações, 2 ed. São Paulo: Rideel, 2016.

MELO, José Augusto de Carvalho e. Extranumerário. Revista de Direito Administrativo, Rio de Janeiro-São Paulo, vol. 1, pp. 347-358, jan. 1945.

MENDONÇA, Rodrigo Gomes de. Teoria da transcendência dos motivos determinantes das decisões do Supremo Tribunal Federal em controle difuso de constitucionalidade, os limites da coisa julgada e o enunciado de súmula vinculante. Revista de Processo. São Paulo, v.36, n.199, pp.307-22, set. 2011.

MITIDIERO, Daniel. Fundamentação e Precedente: dois discursos a partir da decisão judicial. Revista de Processo, São Paulo, n. 206, 2012. 
MORAES, Alexandre de. As súmulas vinculantes no Brasil e a necessidade de limites ao ativismo judicial. Revista da Faculdade de Direito da Universidade de São Paulo. São Paulo, v.106/107, pp. 267-85. jan./dez. 2011/2012.

MOREIRA, José Carlos Barbosa. Súmula, jurisprudência, precedente: uma escalada e seus riscos. Revista Síntese de Direito Civil e Processual Civil. Porto Alegre, v.6, n.35, pp. 516. maio/jun. 2005.

NERY JR., Nelson. Entrevista ao portal eletrônico Jota. Disponível em: [http://jota.info/justica/nucleo-duro-novo-cpc-e-inconstitucional-diz-jurista-21122016]. Acesso em 22.12.2016.

NEUBORNE, Burt. The binding quality of supreme court precedent. Tulane Law Review. New Orleans, v.61, n.5, pp. 991-1007, Abr. 1987.

NEVES, Antonio Castanheira. O problema da constitucionalidade dos assentos: comentário ao Acórdão 810/93 do Tribunal Constitucional. Coimbra: Coimbra Editora, 1994.

NOBRE JÚNIOR, Edilson Pereira. O direito processual brasileiro e o efeito vinculante das decisões dos Tribunais Superiores. Revista dos Tribunais. São Paulo, v. 90, n.785, pp.4672, mar. 2001.

NORTHFLEET, Ellen Gracie. Ainda sobre o efeito vinculante. Cadernos de Direito Tributário e Finanças Públicas. São Paulo, v.4, n.16, p.12-3, jul./set. 1996.

OLIVEIRA, Pedro Miranda de. O papel do STF no novo sistema processual brasileiro. Revista Dialética de Direito Processual. São Paulo, n.118, pp.71-85, jan. 2013.

PORTO, Sergio. Sobre a Common Law, Civil Law e o Precedente Judicial, Academia Brasileira de direito Processual Civil. Disponível em: [www.abdpc.org.br/abdpc/artigos/sergio\%20porto-formatado.pdf].

PORTO, Mario Moacyr. As súmulas do Supremo Tribunal Federal: estudo critico. Revista Forense. Rio de Janeiro, v.93, n.340, out./dez. 1997. 
REIS, Mauricio Martins. Precedentes obrigatórios e sua adequada compreensão interpretativa: de como as súmulas vinculantes não podem ser o bode expiatório de uma hermenêutica jurídica em crise. Revista de Processo. São Paulo, v.38, n.220, pp.207-28, jun. 2013.

ROSAS, Roberto. Direito Sumular. 14 ed. São Paulo: Malheiros, 2012.

SELLERS, Mortimer N. S. The doctrine of precedent in the United States of America. The American Journal of Comparative Law. Baltimore, v.54, pp.67-88, 2006.

SILTALA, Raimo. A Theory of Precedent: from analytical positivism to a post-analytical Philosophy of Law. Oxford: Hart, 2000.

SILVA, De Plácido e. Vocabulário Jurídico. v. 4. Rio: Forense, 1978.

STRECK, Lenio Luiz. Súmulas no Direito Brasileiro: eficácia, poder e função. 2 ed. Porto Alegre: Livraria do Advogado, 1998.

STRECK, Lenio Luiz. Súmulas vinculantes em terrae brasilis: necessitamos de uma teoria para a elaboração de precedentes? Revista Brasileira de Ciências Criminais. São Paulo. v.17, n.78, pp.284-319, maio/jun. 2009.

TARUFFO, Michele. Precedente e Jurisprudência. Revista de Processo, São Paulo, n. 199, pp. 139-245, 2011.

TEIXEIRA, Sálvio de Figueiredo. A súmula e sua evolução no Brasil. Revista Trimestral de Jurisprudência dos Estados. São Paulo. v.24, n.179, p.15-34, nov./dez. 2000.

TUSHNET, Mark V. Self-formalism, precedent and the rule of law. Notre Dame Law Review. Notre Dame, v.72, n.5, pp.1583-95, Jul. 1997.

WAMBIER, Teresa; CONCEIÇÃO, Maria Lúcia; RIBEIRO, Leonardo; MELLO, Rogério. Primeiros Comentários ao Novo Código de Processo Civil. São Paulo: RT, 2015.

WAMBIER, Teresa; DIDIER JR., Fredie; TALAMINI, Eduardo; DANTAS, Bruno. Breves Comentários ao Novo Código de Processo Civil. São Paulo: RT, 2015. 